\title{
Liver abscess and septic shock as an unusual complication after endoscopic ampullectomy
}
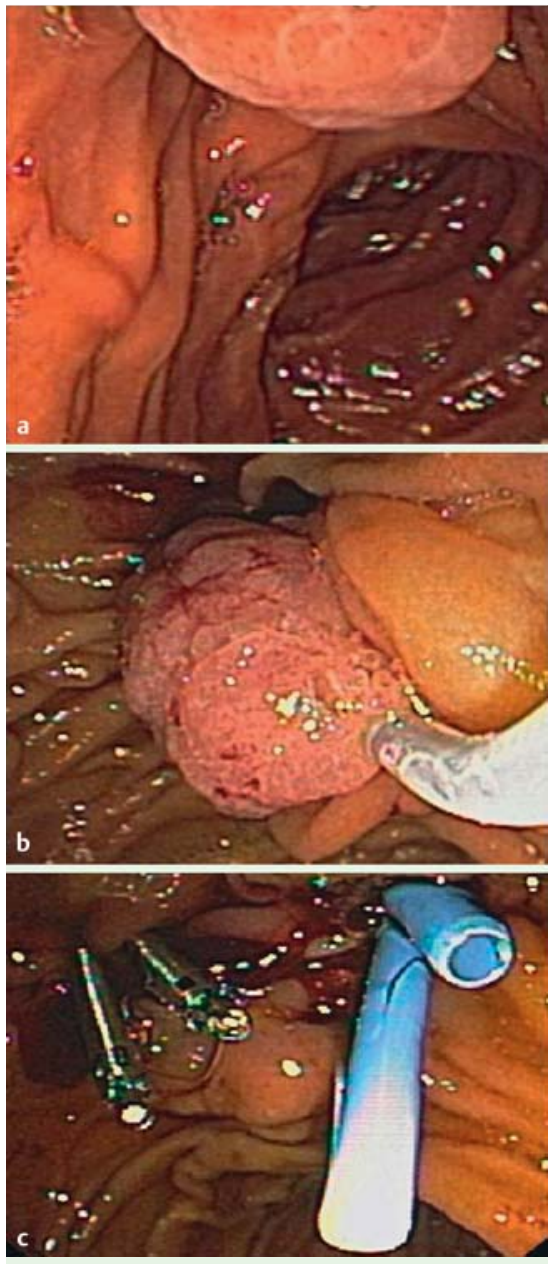

Fig. 1 Endoscopic views: a tumor prior to intervention; $\mathbf{b}$ during the endoscopic procedure, the tumor is encircled with the endoscopic electrocautery loop and then cauterized; $\mathbf{c}$ appearance after removal of the tumor and placement of two stents.

Tumors of the ampulla of Vater represent about $5 \%$ of gastrointestinal neoplasms and are more often identified during upper gastrointestinal endoscopy [1], most are adenomas forming part of the adenoma-carcinoma sequence [2]. The first endoscopic resection of a duodenal adenoma was performed in the $1970 \mathrm{~s}$ [3], since when this procedure has become increasingly common, and the management has shifted from surgical resection to endoscopic procedures [1-4]. We present here the first report in the literature in English, of a major septic complication after endoscopic ampullectomy.

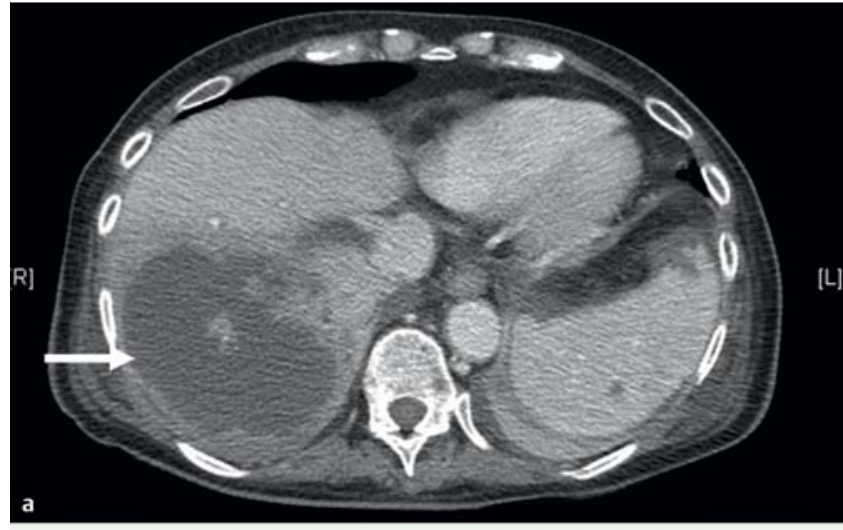

Fig. 2 Abdominal computed tomography (CT) scan showing the abscess located within the liver (arrows): a without contrast. b with contrast.

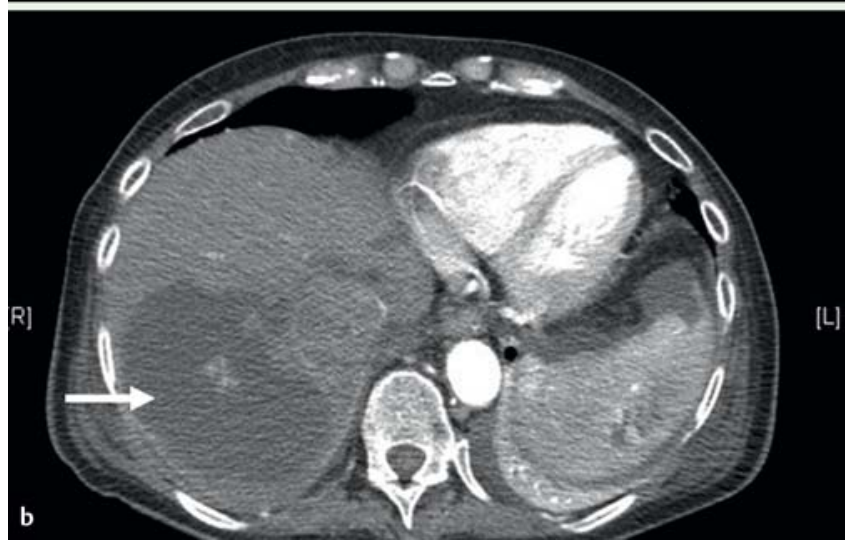

A 61-year-old woman was referred to our center; her abdominal computed tomography (CT) and magnetic resonance imaging (MRI) scans showed a dilated Wirsung duct; an endoscopic ultrasound showed a 15-mm mucosal-submucosal lesion in the major duodenal papilla; a tubulovillous adenoma with low grade dysplasia was diagnosed on biopsy ( $\mathbf{F i g . 1} \mathbf{1}$ ). She therefore underwent endoscopic ampullectomy; in the same session endoscopic retrograde cholangiopancreatography (ERCP) plus sphincterotomy was also performed and stents were placed in the common bile and pancreatic ducts (๑ Figs. 1 b, c).

She was discharged, but readmitted 25 days later because of severe abdominal pain. She had a clinical picture of septic shock and cholangitis, which required broad spectrum antibiotics. Contrast-enhanced abdominal CT demonstrated a $10 \times 6 \mathrm{~cm}$ lesion of the right lobe of the liver compatible with a liver abscess ( Figs. 2a,b).
Percutaneous abdominal drainage, which removed $300 \mathrm{ml}$ of purulent fluid, was performed along with an ERCP, which showed migration of the stents previously positioned and evidence of biliary stenosis that required the placement of a new stent. Her clinical condition subsequently improved, and follow-up abdominal CT and ultrasound scans were performed, which showed evidence of progressive and significant decrease in the size of the hepatic abscess. The patient was discharged 30 days after admission and 4 months later her clinical condition remains good.

Endoscopic ampullectomy is a safe procedure that can be used as first-line therapy, but it can also cause life-threatening complications that should be considered when this therapy is planned.

Endoscopy_UCTN_Code_CPL_1AK_2AI

Competing interests: None 
S. Gruttadauria ${ }^{1,2}$, S. Li Petri ${ }^{1}$,

G. J. Echeverri ${ }^{1}$, C. Ricotta ${ }^{1}$, I. Tarantino ${ }^{3}$, M. Traina ${ }^{3}$, B. Gridelli ${ }^{1,2}$

1 Department of Abdominal and Transplantation Surgery, Mediterranean Institute for Transplantation and Advanced Specialized Therapies (IsMeTT), University of Pittsburgh Medical Center in Italy, Palermo Italy

2 Department of Surgery, University of Pittsburgh Medical Center, Pittsburgh, Pennsylvania, USA

3 Department of Gastroenterology, Mediterranean Institute for Transplantation and Advanced Specialized Therapies (IsMeTT), University of Pittsburgh Medical Center in Italy, Palermo Italy

\section{References}

1 Catalano MF, Linder JD, Chak A et al. Endoscopic management of adenoma of the major duodenal papilla. Gastrointest Endosc 2004; 59: 225-232

2 Eswaran SL, Sanders M, Bernadino KP et al. Success and complications of endoscopic removal of giant duodenal and ampullary polyps: a comparative series. Gastrointest Endosc 2006; 64: 925 - 932

3 Haubrich WS, Johnson RB, Foroozan P. Endoscopic removal of a duodenal adenoma. Gastrointest Endosc 1973; 19: 201

4 Wong RF, DiSario JA. Approaches to endoscopic ampullectomy. Curr Opin Gastroenterol 2004; 20: 460 - 467
Bibliography

DOI $10.1055 / \mathrm{s}-0030-1256261$

Endoscopy 2011; 43: E158 -E159

(c) Georg Thieme Verlag KG Stuttgart · New York . ISSN 0013-726X

\section{Corresponding author}

\section{S. Gruttadauria, MD, PhD}

ISMETT (Istituto Mediterraneo per i Trapianti e Terapie ad Alta Specializzazione)

Via Ernesto Tricomi N. 1

90127 Palermo

Italy

Fax: +39-91-2192400

sgruttadauria@ismett.edu 